\title{
Breast Cancer Resistance Protein and P-Glycoprotein Expression in Patients with Newly Diagnosed and Therapy-Refractory Ulcerative Colitis Compared with Healthy Controls
}

\author{
Heike Gutmann ${ }^{a}$ Petr Hruz ${ }^{a, b}$ Christian Zimmermann ${ }^{a} \quad$ Alexander Straumann $^{d}$ \\ Luigi Terracciano $^{c}$ Felix Hammann ${ }^{a}$ Frank Lehmann ${ }^{b}$ Christoph Beglinger ${ }^{b}$ \\ Juergen Drewe ${ }^{b}$

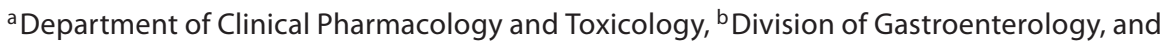 \\ 'Department of Pathology, University Hospital of Basel, Basel, and d Department of Gastroenterology, \\ Kantonsspital Olten, Olten, Switzerland
}

\section{Key Words}

Breast cancer resistance protein - P-glycoprotein •

Transporter expression • Ulcerative colitis · Therapy

refractoriness $\cdot$ Inflammation

\begin{abstract}
Aims: Efflux transporters such as breast cancer resistance protein (BCRP/ABCG2) and P-glycoprotein (Pgp; MDR1/ $A B C B 1)$ are protecting the enterocytes from potentially toxic compounds. Both transporters have been reported to be downregulated in patients with active ulcerative colitis (UC). The aim of this study was to evaluate transporter expression in both unaffected and inflamed mucosa of patients with active UC, in drug-naïve and treated patients with UC and compare the results with transporter expression in healthy subjects. Methods: Transporter expression was determined with real-time RT-PCR (TaqMan) in inflamed and unaffected mucosa of newly diagnosed $(n=12)$ and therapy-refractory $(n=11)$ patients with UC. Expression levels were compared with UC patients in remission $(n=11)$ and control subjects $(n=26)$. BCRP and Pgp expression was evaluated by immu-
\end{abstract}

\section{KARGER}

Fax +41613061234 E-Mail karger@karger.ch www.karger.com
(C) 2008 S. Karger AG, Basel

0012-2823/08/0783-0154\$24.50/0

Accessible online at:

www.karger.com/dig nohistochemistry. Results: Compared with unaffected mucosa, BCRP expression was significantly reduced in inflamed mucosa of newly diagnosed drug-naïve patients with UC (expression reduced to $30 \%$ ) as well as in patients not responding to treatment (reduced to $25 \%$ ) with either 5 -aminosalicylates $(n=7)$ or prednisone $(n=4)$. Unaffected mucosa of UC patients showed comparable transporter expression to unaffected mucosa of control subjects. MDR1 expression depicts a similar pattern. Protein staining for Pgp and BCRP was significantly reduced in the inflamed mucosa of patients with active UC. Conclusions: Expression of both efflux transporters BCRP and MDR1 is reduced, but only in inflamed tissue of patients with active UC. Transporter expression in unaffected mucosa of patients with active UC is comparable to healthy controls. The data suggest that the inflammatory process is responsible for the reduced levels. A major role in the pathogenesis of $U C$ is unlikely.

Copyright $\odot 2008$ S. Karger AG, Basel

H.G. and P.H. contributed equally to this study.
Juergen Drewe, MD, MSc

Department of Clinical Pharmacology and Toxicology, University Clinic Basel Hebelstrasse 2

$\mathrm{CH}-4031$ Basel (Switzerland)

Tel. +41 61265 3848, Fax +41 61265 8581, E-Mail juergen.drewe@unibas.ch 


\section{Introduction}

Breast cancer resistance protein (BCRP/ABCG2) as well as P-glycoprotein (Pgp; MDR1/ABCB1) are members of the ATP-binding cassette (ABC) transporter family. Both were first detected in multi-drug resistant tumor cells $[1,2]$. Both have a protective function against potentially toxic xenobiotics and are highly expressed in tissues that are important for uptake and elimination of toxic substances such as the intestine, the kidney, the liver, and the blood brain barrier [3-7]. BCRP and Pgp are localized in the apical membrane of intestinal cells, where they limit the absorption of orally administered drugs and ingested toxins such as the BCRP substrates PhIP (2amino-1-methyl-6-phenylimidazo[4,5-b]pyridine), benzo[a]pyrene [8] and the chlorophyll-derived phototoxin pheophorbide a $[9,10]$ or the Pgp substrates digoxin, ciclosporin or verapamil [11-13]. These findings indicate that both transporters exhibit a role in maintaining the barrier function of the intestinal epithelium. Several drugs (such as dexamethasone [14] and sulphasalazine [15]) used in the treatment of inflammatory bowel disease are transported by Pgp and BCRP.

Previous studies with gene arrays and quantitative RTPCR have reported that MDR1/ABCB1 (the gene of Pgp), and BCRP are downregulated in patients with active ulcerative colitis (UC) [16-19]. Genetic variation analysis of MDR1 indicates that this gene locus is associated with susceptibility for UC $[20,21]$.

These studies did, however, not differentiate between the transporter expression patterns in tissue samples obtained from inflamed or unaffected mucosa of the same individuals and did not take into account whether the patients with UC received previous or concomitant antiinflammatory treatment. Since it is well known that several drugs such as the antimycobacterial drug rifampicin or the antidepressant St. John's wort are able to change the expression of Pgp [22, 23], it is important to investigate whether the medication used in UC might influence MDR1 and/or BCRP mRNA expression.

Therefore, MDR1 and BCRP expression was investigated in newly diagnosed untreated patients with UC, patients with UC not responding to anti-inflammatory medication, UC patients in remission and healthy controls. In patients with active UC, it was of special interest to evaluate transporter expression in unaffected and inflamed mucosa. We hypothesized that gene expression of MDR1 and BCRP may be altered in UC.

BCRP and P-gp Expression in Ulcerative Colitis

\section{Materials and Methods}

\section{Patient Characteristics}

In this study, 12 patients with newly diagnosed UC, 11 patients with active UC (refractory to treatment), 11 patients in remission and 26 control subjects were enrolled after having given their informed consent. For detailed patient characteristics, see table 1. Diagnosis of patients with UC was based on a typical clinical history, laboratory findings as well as endoscopic and histological criteria. Tissue biopsies were sampled by experienced gastroenterologists. From patients with active disease (newly diagnosed patients and patients with refractory disease) biopsies were taken from the inflamed and from the unaffected region. In two newly diagnosed patients, biopsies could only be obtained of the inflamed mucosa due to macroscopic signs of pancolitis. Unaffected areas were defined as mucosa regions without any macroscopic/endoscopic signs of inflammation (ulceration, edema, discoloration, hemorrhagic appearance or mucinous/fibrinous coating); these biopsies were obtained at least $10-15 \mathrm{~cm}$ distant from the pathologic area. Control subjects had an indication for a gastrointestinal tract endoscopy within a cancer screening program. Biopsy specimens were obtained during routine endoscopy from the colon, submerged in RNAlater solution (Qiagen, Hilden, Germany) and stored at $-80^{\circ} \mathrm{C}$ until further processing. The study protocol and consent forms were approved by the State Ethical Committee of Basel prior to the start of the study.

\section{Real-Time RT-PCR Analysis (TaqMan)}

Total RNA was isolated from 2 biopsies from each subject. RNA was extracted using the RNeasy Mini Kit (Qiagen) following the instructions provided by the manufacturer. RNA was quantified with a GeneQuant photometer (Pharmacia, Uppsala, Sweden). After DNase I digestion (Gibco Life Technologies, Basel, Switzerland), $1.5 \mu \mathrm{g}$ of total RNA was reverse-transcribed by $\mathrm{Su}-$ perscript (Gibco Life Technologies) according to the manufacturer's protocol using random hexamers as primers.

TaqMan analysis was carried out on a 7900HT Sequence Detection System (Applied Biosystems, Rotkreuz, Switzerland) as previously described in recent papers of our group [4, 24, 25]. In brief, standards for mRNA quantification were obtained by classical PCR using duodenal cDNA as a template. Primers for generating the standards and primers/probes for TaqMan analysis were designed according to the guidelines of Applied Biosystems with the help of the Primer Express 2.0 software (corresponding sequences are displayed in table 1). All samples were run in triplicates and were quantified using a standard curve. Not reversetranscribed RNA served as a negative control. For each sample the transcript numbers of BCRP, MDR1 and of villin were determined. By calculating the ratio of BCRP/villin and MDR1/villin, the mRNA expression was normalized. This approach has been established to account for variations in the enterocyte content of biopsies $[3,26]$.

\section{Immunohistochemistry}

Human duodenal tissue fragments were mounted in OCT compound (Sakura Finetek, Zooterwoude, The Netherlands), snap-frozen in liquid nitrogen and stored at $-80^{\circ} \mathrm{C}$. Frozen sections $(5 \mu \mathrm{m})$ were air dried overnight and a periodate-lysine paraformaldehyde solution (3\%) was used for postfixation. Then 
Table 1. Patient characteristics

\begin{tabular}{|c|c|c|c|c|}
\hline & $\begin{array}{l}\text { Patients newly } \\
\text { diagnosed with } \\
\mathrm{UC}(\mathrm{n}=12)\end{array}$ & $\begin{array}{l}\text { Patients with active } \\
\text { UC refractory to } \\
\text { therapy }(n=11)\end{array}$ & $\begin{array}{l}\text { Patients in } \\
\text { remission } \\
(\mathrm{n}=11)\end{array}$ & $\begin{array}{l}\text { Control } \\
\text { subjects } \\
(\mathrm{n}=26)\end{array}$ \\
\hline Median age (range), years & $55(27-78)$ & $55(27-77)$ & $42(24-69)$ & $56(24-78)$ \\
\hline Sex & $4 \mathrm{M} / 8 \mathrm{~F}$ & $7 \mathrm{M} / 4 \mathrm{~F}$ & $4 \mathrm{M} / 7 \mathrm{~F}$ & $13 \mathrm{M} / 13 \mathrm{~F}$ \\
\hline Mean BMI \pm SEM & $23.9 \pm 0.9$ & $24.5 \pm 1.5$ & $24.3 \pm 0.9$ & $27.8 \pm 1.2$ \\
\hline Mean clinical activity index \pm SEM & $5.2 \pm 0.7$ & $6.8 \pm 0.9$ & $1.4 \pm 0.5$ & - \\
\hline Medication & none & & & none \\
\hline \multicolumn{5}{|l|}{ Patients with aminosalicylates } \\
\hline$>3$ g/day & - & 7 & 2 & - \\
\hline $2-3$ g/day & - & - & 1 & - \\
\hline \multicolumn{5}{|l|}{ Patients with steroids } \\
\hline$>40 \mathrm{mg} /$ day & - & 2 & - & - \\
\hline $10-39 \mathrm{mg} /$ day & - & 1 & - & - \\
\hline$<10 \mathrm{mg} /$ day & - & 1 & 1 & - \\
\hline \multicolumn{5}{|l|}{ Patients with immunosuppressive drug } \\
\hline Azathioprine $100-150 \mathrm{mg} /$ day & - & 1 (+40 mg prednisone) & 4 & - \\
\hline
\end{tabular}

the sections were washed with washing solution $(\mathrm{TBS} / \mathrm{NaCl}$, Tween $0.05 \%$ ) and incubated with normal horse serum for $30 \mathrm{~min}$ at room temperature as blocking solution. For BCRP staining, the tissue sections were incubated with a 1:1,240 dilution of the BCRP monoclonal antibody BXP-21 (Alexis Biochemicals, Lausen, Switzerland) overnight at $4^{\circ} \mathrm{C}$ or for Pgp staining with the Pgp monoclonal antibody ISB1-PGP with a 1:50 dilution. Samples were washed three times with washing solution and incubated with the horse antimouse IgG secondary antibody for 30 min at room temperature. After three washes with the washing solution, a perhydrol solution $\left[\mathrm{H}_{2} \mathrm{O}_{2}(0.3 \%)\right.$, sodium azide $(0.1 \%)$ in PBS] was used to destroy the endogenous peroxidase activity. The staining was performed with the avidin/biotinylated enzyme complex (ABC method) according to the manufacturer's instructions (Vectastain, Elite kit, Vector Laboratories, Burlingane, Calif., USA). For detection, 3-amino-9-ethylcarbazole, which forms a red end product, was used (Biogenex, San Ramon, Calif., USA). Sections which served as negative controls were treated equally, except that they were not incubated with the primary antibody.

Semiquantitative analysis of Pgp and BCRP staining was performed in biopsies of control subjects (Pgp $n=7$; BCRP $n=4)$, of patients with newly diagnosed UC in inflamed (Pgp $n=4$; BCRP $\mathrm{n}=3$ ) vs. unaffected tissue ( $\operatorname{Pgp} \mathrm{n}=3$; BCRP $n=3)$ as well as of patients with therapy-refractory UC in inflamed (Pgp $\mathrm{n}=4$; BCRP $n=3)$ vs. unaffected tissue (Pgp $n=3$; BCRP $n=3)$ and of patients in remission ( $\operatorname{Pgp} n=6 ;$ BCRP $n=3)$. Rating of protein staining on blinded specimens was done by a trained pathologist. Expression levels were rated as follows: $0=$ no expression, $1=$ low, 2 = intermediate, $3=$ high expression.

\section{Statistics}

All values were expressed as means \pm SEM. UC patients MDR1 and BCRP expression was compared with that of control subjects by analysis of variance and subsequent Dunnett multi- comparison test. All comparisons were performed as two-sided comparisons using the SPSS for Windows software (version 14.0). The level of significance was set at $\mathrm{p}<0.05$.

\section{Results}

\section{BCRP and MDR 1 mRNA Expression Is \\ Downregulated in the Inflamed Mucosa of Patients \\ with Active UC}

BCRP, MDR1 and villin mRNA expression was analyzed in 26 control subjects and compared with patients with newly diagnosed UC (10 biopsy specimens from unaffected mucosa and 12 from inflamed mucosa), patients with active UC and refractory to anti-inflammatory medication (11 biopsy specimens from unaffected mucosa and 12 from inflamed mucosa) and UC patients in remission without any signs of acute disease.

BCRP in the inflamed mucosa of newly diagnosed untreated UC patients was reduced to $30 \%$ when compared with the unaffected mucosa (fig. 1a). Mean BCRP mRNA expression \pm SEM was $0.009 \pm 0.002$ in the inflamed and $0.032 \pm 0.005$ in the unaffected mucosa. Similarly, in patients with active UC refractory to anti-inflammatory treatment, BCRP mRNA expression was significantly $(\mathrm{p}=0.006)$ reduced to $35 \%$ in inflamed mucosa $(0.009$ $\pm 0.003)$, when compared with control subjects $(0.026 \pm$ $0.0029 ; \mathrm{p}=0.005)$. Patients treated with 5-aminosalicylates $(n=7)$ showed an 8 -fold reduction in BCRP expres- 


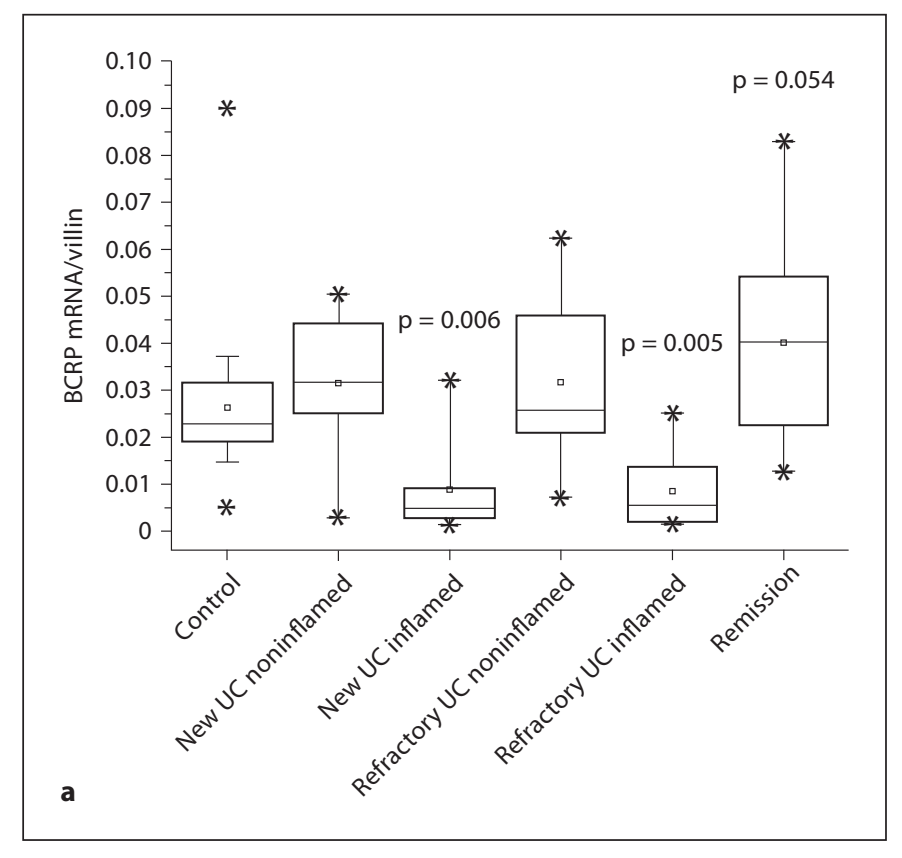

Fig. 1. a BCRP mRNA expression (BCRP/villin) in 26 healthy subjects, in colonic tissue sections with no visible inflammation of 10 newly diagnosed UC patients and in 12 acute inflamed tissue sections of newly diagnosed UC patients, in colonic tissue sections with no visible signs of inflammation of 11 therapy-refractory patients and in 12 acute inflamed tissue sections of therapyrefractory patients, in tissue sections of 17 UC patients in remission. Data represent means \pm SEM. Statistical comparisons with controls were obtained. b MDR1 mRNA expression (MDR1/vil-

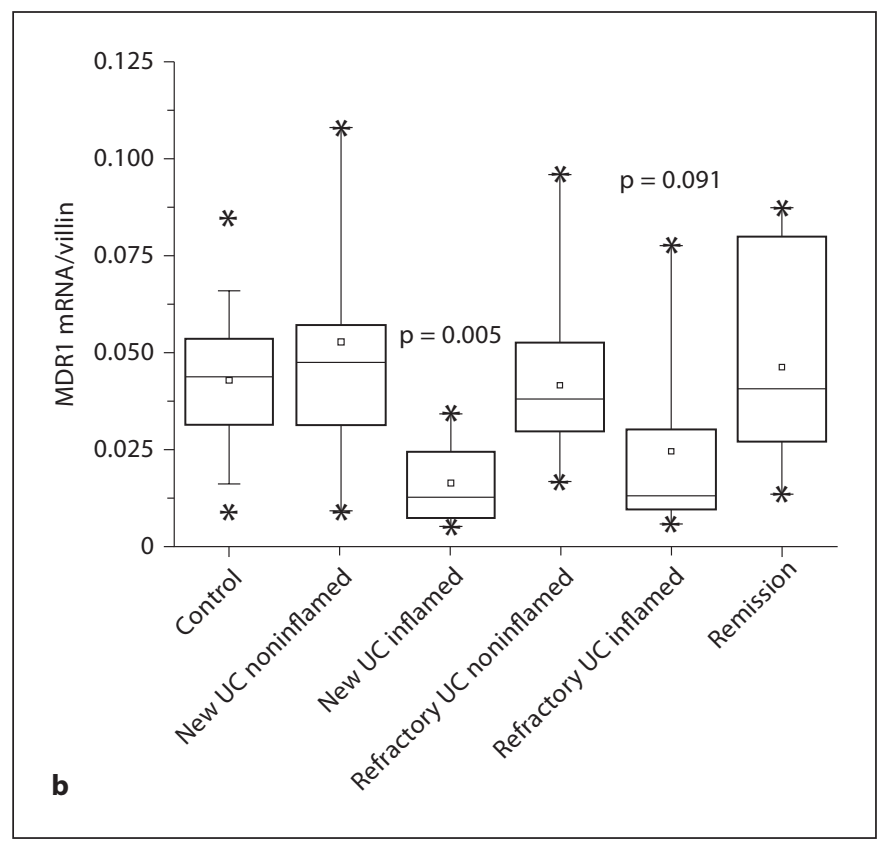

lin) in 26 healthy subjects, in colonic tissue sections with no visible inflammation of 9 newly diagnosed UC patients and in 11 tissue sections from acutely inflamed sites of newly diagnosed UC patients, in colonic tissue sections with no visible signs of inflammation of 11 therapy-refractory patients and in 12 tissue sections from acutely inflamed sites of therapy-refractory patients, and in tissue sections obtained from 17 UC patients in remission. Data represent means \pm SEM. Statistical comparisons with controls were obtained. sion in the inflamed mucosa $(0.005 \pm 0.001)$ versus unaffected mucosa $(0.04 \pm 0.006)$, whereas only an insignificant decrease for prednisone-treated patients $(n=4)$ was observed.

Almost identical BCRP expression levels were observed in the unaffected mucosa of patients with active UC (newly diagnosed and refractory to anti-inflammatory medication) and in the unaffected mucosa of control subjects. BCRP mRNA levels of UC patients in remission $(0.040 \pm$ $0.006)$ were higher compared with control subjects. This increase was borderline significant $(\mathrm{p}=0.054)$.

Similar findings were observed for MDR1 mRNA expression. In inflamed mucosa of patients with active UC, independent if newly diagnosed or refractory to treatment, MDR1 showed lower expression levels when compared with the unaffected mucosa (fig. 1b). In control subjects, mean MDR1 \pm SEM expression was $0.043 \pm$ 0.003 , in newly diagnosed UC patients $0.016 \pm 0.003$ in the inflamed $(\mathrm{p}=0.005)$ and $0.053 \pm 0.011$ in the unaffected mucosa. In therapy-refractory patients with the in- flamed mucosa, mean MDR1/villin expression was 0.025 \pm 0.007 (which was borderline significantly lower than in controls, $p=0.091$ ) and $0.042 \pm 0.006$ in the unaffected mucosa. Again, patients treated with 5-aminosalicylates showed significantly reduced MDR1 expression in the inflamed mucosa, $0.011 \pm 0.002$ versus 0.037 \pm 0.005 in the unaffected tissue. MDR 1 expression in UC patients in remission $(0.049 \pm 0.008)$ was comparable to control subjects.

\section{BCRP and Pgp Levels Are Reduced in the Inflamed Mucosa in Patients with Active UC}

Expression of BCRP and Pgp was evaluated by immunohistochemistry in control subjects, newly diagnosed, and therapy-refractory patients with UC, as well as UC patients in remission. In the group of newly diagnosed and therapy-refractory patients, tissue samples obtained from inflamed mucosa and samples from unaffected mucosal sites were analyzed separately. 


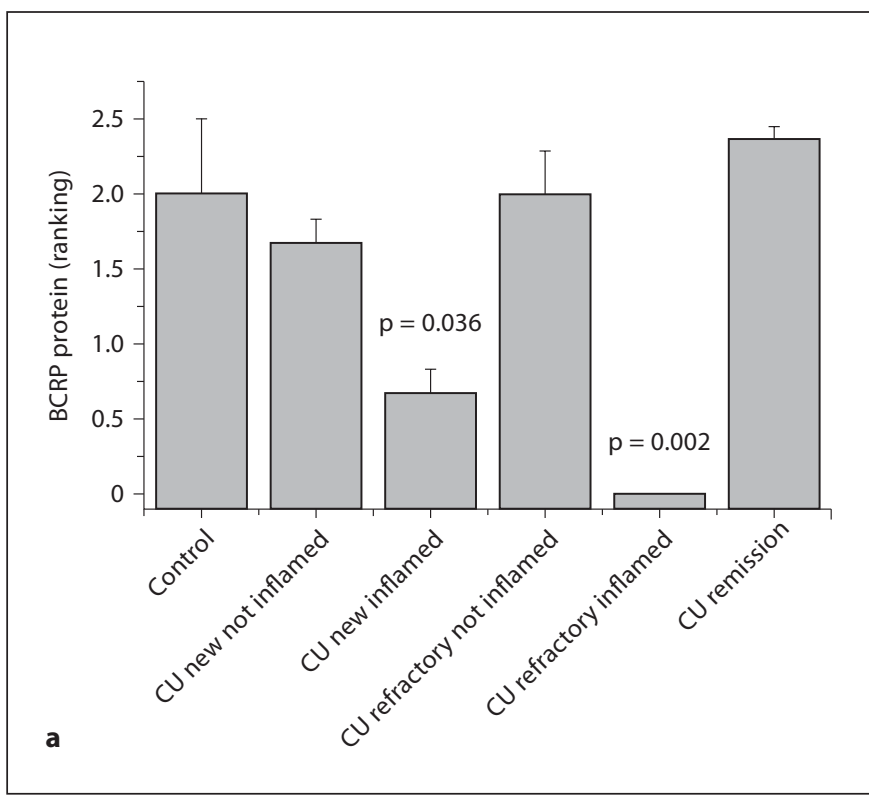

Fig. 2. a BCRP amount in selected healthy subjects, in colonic tissue sections with no visible signs of inflammation of 10 newly diagnosed UC patients and in 12 tissue sections obtained from acutely inflamed sections of newly diagnosed UC patients, in colonic tissue sections with no visible signs of inflammation of 11 therapy-refractory patients and in 12 tissue samples from acutely inflamed sections of therapy-refractory patients, in tissue sections of 17 UC patients in remission. Data represent means \pm SEM. Statistical comparisons with controls were obtained. b Pgp

As expected, both $\mathrm{ABC}$ transporter proteins were localized on the apical membrane of the epithelial cells (see fig. 3 , 4). Pgp and BCRP were significantly reduced in inflamed mucosa of newly diagnosed as well as therapy-refractory patients. Protein expression in the unaffected tissue of control subjects was comparable with expression in unaffected tissue of UC patients with active disease as well as in UC patients in remission (fig. 2). In tissue sections from the inflamed mucosa, BCRP expression was reduced by $63 \%$ in newly diagnosed and was even completely abolished in therapy-refractory UC patients when compared with control subjects (fig. 2a). Similarly, Pgp expression was reduced by about $85 \%$ in the inflamed mucosa of patients with active UC compared with control subjects (fig. 2b).

Representative pictures of immunohistochemistry with staining for BCRP are displayed in figure 3 and for Pgp in figure 4.

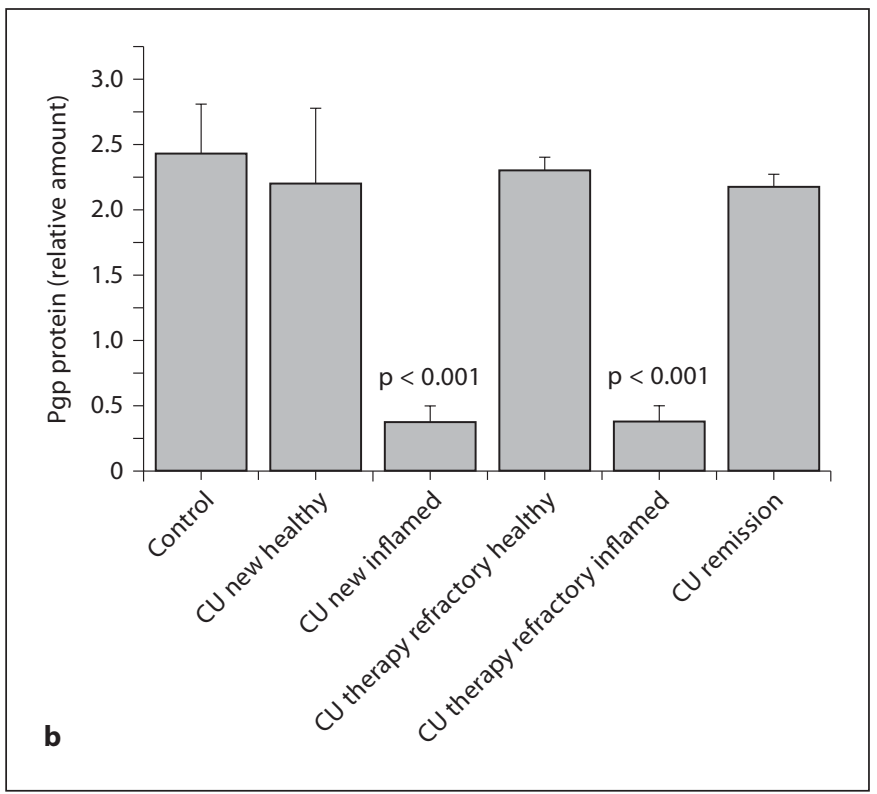

amount in selected healthy subjects, in colonic tissue sections with no visible signs of inflammation of 10 newly diagnosed UC patients and in 12 tissue sections obtained from acutely inflamed sites of newly diagnosed UC patients, in colonic tissue sections obtained from sites with no visible signs of inflammation of 11 therapy-refractory patients and in 12 tissue sections obtained from acutely inflamed sites of therapy-refractory patients, in tissue sections of 17 UC patients in remission. Data represent means \pm SEM. Statistical comparisons with controls were obtained.

\section{Discussion}

The results of this study demonstrate that expression of BCRP and MDR1 is downregulated in patients with $\mathrm{UC}$ on the transcriptional and protein levels, but only in the inflamed mucosa. On the other hand, both transporters show a similar expression level in gut biopsies from unaffected sites of patients with active UC, in samples from patients in remission and in biopsies from noninflamed parts of the gut of control subjects. The reduction in transporter expression in inflamed mucosa of untreated newly diagnosed UC patients was similar to that in patients who have failed treatment with 5-ASA or corticosteroids, which suggests that this reduction is largely dependent on the inflammation rather than the anti-inflammatory treatment.

Efflux transport proteins are important components of the intestinal barrier against bacterial toxins, carcinogens and drugs [3-7, 9-13]. Altered expression of transport proteins and/or altered function of these proteins 
Fig. 3. Immunohistochemical staining of BCRP on the apical membrane of human duodenal epithelial cells using the BCRP antibody BXP-21. a Healthy subject. b Newly diagnosed UC patient, noninflamed tissue. c Newly diagnosed UC patient, inflamed tissue. d Therapy-refractory UC patient, noninflamed tissue. e Therapy-refractory UC patient, inflamed tissue. $\mathbf{f} \mathrm{UC}$ patient in remission.
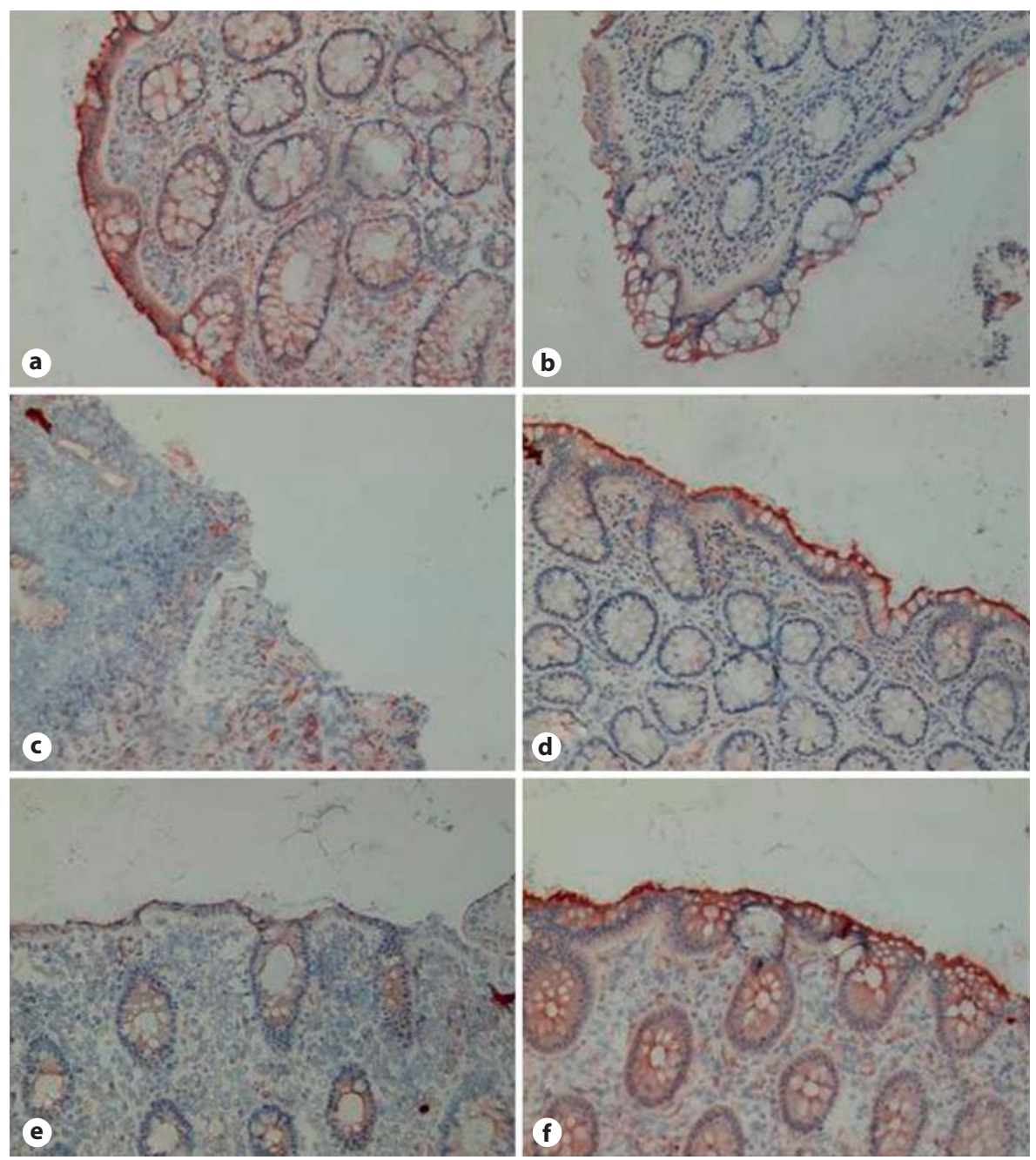

have been proposed to contribute to the pathogenesis of inflammatory disorders [16-21]. Here, we document that two of the efflux transporters of importance for the barrier function of the gastrointestinal mucosa, Pgp and BCRP, are expressed at markedly reduced levels in the inflammatory areas of the colon in patients with UC. This is in keeping with a recent study by Englund et al. [18] who also showed that BCRP and Pgp expression was reduced in inflamed tissue of UC patients that were taking anti-inflammatory drugs. We furthermore demonstrate that BCRP mRNA levels of patients with UC in remission are increased as compared with control subjects. These findings suggest that the inflammation itself might be responsible for the observed effects. Inflammation is known to suppress the expression and activity of several efflux transporters; also, the expression and function of intestinal mdr1 and mrp2 are reduced in a rat model of intestinal inflammation. Here, we extend these observations by showing that BCRP and MDR1 expression is reduced in the inflamed part compared with noninflamed tissue in individuals with active disease. Finally, the effect of drug treatment on the expression of these two transporters is related to their anti-inflammatory activity: patients that were treated with 5-aminosalicylates $(\mathrm{n}=7)$ and did not respond to this treatment showed a considerable suppression in BCRP and MDR1 expression in the inflamed mucosa when compared with the unaffected area. On the other hand, patients treated with prednisone $(n=4)$ showed only an unremarkable and insignificant decrease in both transporters. Although prednisone was identified as a substrate for Pgp [27], it is not known to induce Pgp or BCRP. We conclude, therefore, that the reduced expression observed for the two transporters is a direct result of the inflammation. The find- 
Fig. 4. Immunohistochemical staining of Pgp on the apical membrane of human duodenal epithelial cells using the Pgp antibody ISB1-PGP. a Healthy subject. b Newly diagnosed UC patient, noninflamed tissue. c Newly diagnosed UC patient, inflamed tissue. d Therapy-refractory UC patient, noninflamed tissue. e Therapy-refractory UC patient, inflamed tissue. f UC patient in remission.
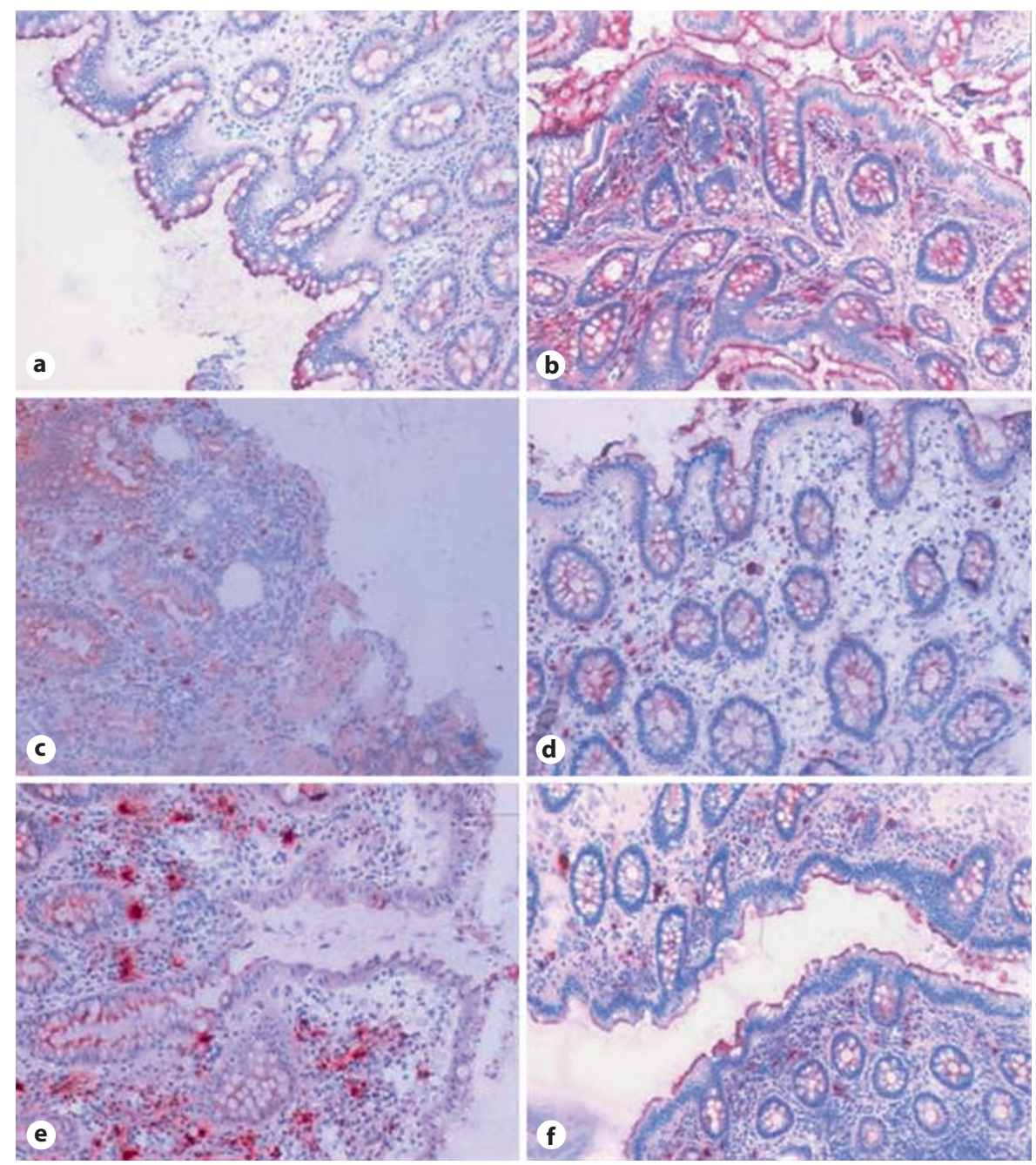

ings furthermore suggest that the two transporters are most likely not involved in the pathogenesis of UC.

It is well known that the expression and activity of a number of hepatic efflux transporters such as MRP2, MRP3, MRP4, and organic anion-transporting polypeptides are diminished during inflammatory processes [28-30]. Alterations in transporter expression do not only occur in the liver, but also in kidney and intestine. Recently, we reported a decrease in BCRP expression in cholestatic patients [31] indicating that BCRP downregulation might be a phenomenon also observed in other gastrointestinal diseases. In vitro data indicate that the transcriptional regulation of BCRP is mediated via the Ah receptor [8], whereas Pgp is regulated by PXR [32]. Several proinflammatory cytokines have been shown to influence transporter gene expression [33, 34]. In fact, Evseenko et al. [35] found that incubation of primary term trophoblasts with TNF- $\alpha$ or IL- $1 \beta$ decreased mRNA and protein expression of Pgp and BCRP to $40-50 \%$, respectively. They could also show that TNF- $\alpha$ affects BCRP expression also at a functional level leading to increased mitoxantrone accumulation [35]. The mechanisms leading to the observed downregulation have to be elaborated.

As both transporters are potent efflux pumps for a variety of toxic compounds, a diminished expression might disturb the intestinal barrier and the excretory function of the gut. A reduced intestinal expression of BCRP and Pgp in inflamed mucosal sites could substantially contribute to the accumulation of carcinogens and other harmful substances (bile acids) in enterocytes. This in turn might partly explain the observation that patients with UC have a higher risk of developing colorectal carcinomas $[36,37]$. 
In conclusion, we have shown that patients with UC exhibit a decreased expression of BCRP and MDR1, both on the mRNA and protein levels in inflamed sites of the mucosa. The data together with published information suggest that the inflammatory process is responsible for the reduced levels. A major role in the pathogenesis of $\mathrm{UC}$ is unlikely. However, a decreased expression of these transporters might increase the accumulation of foodderived carcinogens and toxins and might influence the pharmacokinetics and effects of anti-inflammatory drugs used in the treatment of UC.

\section{Acknowledgments}

We are very thankful to Uschi Behrens, Ursula Dürrmüller and Brigitte Schneider for their excellent technical assistance. The study was supported by SMCCV (Schweizerische Morbus Crohn/ Colitis Ulcerosa Vereinigung, Aarau, Switzerland) and by an unconditional research grant from UCB-Pharma Ltd., Bulle, Switzerland (C.B.).

\section{References}

1 Doyle LA, Yang W, Abruzzo LV, Krogmann T, Gao Y, Rishi AK, Ross DD: A multidrug resistance transporter from human MCF-7 breast cancer cells. Proc Natl Acad Sci USA 1998;95:15665-15670.

-2 Miyake K, Mickley L, Litman T, Zhan Z, Robey R, Cristensen B, Brangi M, Greenberger L, Dean M, Fojo T, Bates SE: Molecular cloning of CDNAS which are highly overexpressed in mitoxantrone-resistant cells: demonstration of homology to $\mathrm{ABC}$ transport genes. Cancer Res 1999;59:8-13.

-3 Taipalensuu J, Tornblom H, Lindberg G, Einarsson C, Sjoqvist F, Melhus H, Garberg P, Sjostrom B, Lundgren B, Artursson P: Correlation of gene expression of ten drug efflux proteins of the ATP-binding cassette transporter family in normal human jejunum and in human intestinal epithelial Caco-2 cell monolayers. J Pharmacol Exp Ther 2001;299:164-170.

4 Zimmermann C, Gutmann H, Hruz P, Gutzwiller JP, Beglinger C, Drewe J: Mapping of multidrug resistance gene 1 and multidrug resistance-associated protein isoform 1 to 5 MRNA expression along the human intestinal tract. Drug Metab Dispos 2005;33:219224.

5 Maliepaard M, Scheffer GL, Faneyte IF, van Gastelen MA, Pijnenborg AC, Schinkel AH, van De Vijver MJ, Scheper RJ, Schellens JH: Subcellular localization and distribution of the breast cancer resistance protein transporter in normal human tissues. Cancer Res 2001;61:3458-3464.

-6 Tanaka Y, Slitt AL, Leazer TM, Maher JM, Klaassen CD: Tissue distribution and hormonal regulation of the breast cancer resistance protein (BCRP/ABCG2) in rats and mice. Biochem Biophys Res Commun 2005; 326:181-187.

7 Mao Q, Unadkat JD: Role of the breast cancer resistance protein (ABCG2) in drug transport. AAPS J 2005;7:E118-E133.
8 Ebert B, Seidel A, Lampen A: Identification of BCRP as transporter of benzo[a]pyrene conjugates metabolically formed in Caco-2 cells and its induction by ah-receptor agonists. Carcinogenesis 2005;26:1754-1763.

-9 van Herwaarden AE, Jonker JW, Wagenaar E, Brinkhuis RF, Schellens JH, Beijnen JH, Schinkel AH: The breast cancer resistance protein (BCRP1/ABCG2) restricts exposure to the dietary carcinogen 2-amino-1-methyl-6-phenylimidazo[4,5-b]pyridine. Cancer Res 2003;63:6447-6452.

10 Jonker JW, Buitelaar M, Wagenaar E, Van Der Valk MA, Scheffer GL, Scheper RJ, Plosch T, Kuipers F, Elferink RP, Rosing H, Beijnen JH, Schinkel AH: The breast cancer resistance protein protects against a major chlorophyll-derived dietary phototoxin and protoporphyria. Proc Natl Acad Sci USA 2002;99:15649-15654.

11 Pauli-Magnus C, von Richter O, Burk O, Ziegler A, Mettang T, Eichelbaum M, Fromm MF: Characterization of the major metabolites of verapamil as substrates and inhibitors of P-glycoprotein. J Pharmacol Exp Ther 2000;293:376-382.

12 Mayer U, Wagenaar E, Beijnen JH, Smit JW, Meijer DK, van Asperen J, Borst P, Schinkel AH: Substantial excretion of digoxin via the intestinal mucosa and prevention of longterm digoxin accumulation in the brain by the mdr la p-glycoprotein. Br J Pharmacol 1996;119:1038-1044.

13 Lown KS, Mayo RR, Leichtman AB, Hsiao HL, Turgeon DK, Schmiedlin-Ren P, Brown MB, Guo W, Rossi SJ, Benet LZ, Watkins PB: Role of intestinal P-glycoprotein (mdr1) in interpatient variation in the oral bioavailability of cyclosporine. Clin Pharmacol Ther 1997;62:248-260.

14 Mark PJ, Waddell BJ: P-glycoprotein restricts access of cortisol and dexamethasone to the glucocorticoid receptor in placental BeWo cells. Endocrinology 2006;147:5147-5152.
15 van der Heijden J, de Jong MC, Dijkmans BA, Lems WF, Oerlemans R, Kathmann I, Schalkwijk CG, Scheffer GL, Scheper RJ, Jansen G: Development of sulfasalazine resistance in human $t$ cells induces expression of the multidrug resistance transporter ABCG2 (BCRP) and augmented production of TNFalpha. Ann Rheum Dis 2004;63:138143.

16 Langmann T, Moehle C, Mauerer R, Scharl M, Liebisch G, Zahn A, Stremmel W, Schmitz G: Loss of detoxification in inflammatory bowel disease: dysregulation of pregnane $\mathrm{X}$ receptor target genes. Gastroenterology 2004;127:26-40.

17 Lawrance IC, Fiocchi C, Chakravarti S: Ulcerative colitis and Crohn's disease: distinctive gene expression profiles and novel susceptibility candidate genes. Hum Mol Genet 2001;10:445-456.

18 Englund G, Jacobson A, Rorsman F, Artursson P, Kindmark A, Ronnblom A: Efflux transporters in ulcerative colitis: decreased expression of BCRP (ABCG2) and Pgp (ABCB1). Inflamm Bowel Dis 2007;13:291297.

19 Blokzijl H, Vander Borght S, Bok LI, Libbrecht $L$, Geuken M, van den Heuvel FA, Dijkstra G, Roskams TA, Moshage H, Jansen PL, Faber KN: Decreased P-glycoprotein (Pgp/MDR1) expression in inflamed human intestinal epithelium is independent of PXR protein levels. Inflamm Bowel Dis 2007;13: 710-720.

20 Schwab M, Schaeffeler E, Marx C, Fromm MF, Kaskas B, Metzler J, Stange E, Herfarth H, Schoelmerich J, Gregor M, Walker S, Cascorbi I, Roots I, Brinkmann U, Zanger UM, Eichelbaum M: Association between the c3435t mdrl gene polymorphism and susceptibility for ulcerative colitis. Gastroenterology 2003;124:26-33. 
21 Ho GT, Nimmo ER, Tenesa A, Fennell J, Drummond H, Mowat C, Arnott ID, Satsangi J: Allelic variations of the multidrug resistance gene determine susceptibility and disease behavior in ulcerative colitis. Gastroenterology 2005;128:288-296.

-22 Westphal K, Weinbrenner A, Zschiesche M, Franke G, Knoke M, Oertel R, Fritz P, von Richter O, Warzok R, Hachenberg T, Kauffmann HM, Schrenk D, Terhaag B, Kroemer HK, Siegmund W: Induction of P-glycoprotein by rifampin increases intestinal secretion of talinolol in human beings: a new type of drug/drug interaction. Clin Pharmacol Ther 2000;68:345-355.

-23 Johne A, Brockmoller J, Bauer S, Maurer A, Langheinrich M, Roots I: Pharmacokinetic interaction of digoxin with an herbal extract from St John's wort (Hypericum perforatum). Clin Pharmacol Ther 1999;66:338-345.

-24 Gutmann H, Hruz P, Zimmermann C, Beglinger $\mathrm{C}$, Drewe J: Distribution of breast cancer resistance protein (BCRP/ABCG2) MRNA expression along the human GI tract. Biochem Pharmacol 2005;70:695-699.

25 Hruz P, Zimmermann C, Gutmann H, Degen L, Beuers U, Terracciano L, Drewe J, Beglinger C: Adaptive regulation of the ileal apical sodium dependent bile acid transporter (ASBT) in patients with obstructive cholestasis. Gut 2006;55:395-402.
26 Lown KS, Bailey DG, Fontana RJ, Janardan SK, Adair CH, Fortlage LA, Brown MB, Guo W, Watkins PB: Grapefruit juice increases felodipine oral availability in humans by decreasing intestinal CYP3A protein expression. J Clin Invest 1997;99:2545-2553.

27 Dilger K, Schwab M, Fromm MF: Identification of budesonide and prednisone as substrates of the intestinal drug efflux pump Pglycoprotein. Inflamm Bowel Dis 2004;10: 578-583.

28 Goralski KB, Hartmann G, Piquette-Miller M, Renton KW: Downregulation of mdrla expression in the brain and liver during CNS inflammation alters the in vivo disposition of digoxin. Br J Pharmacol 2003;139:35-48.

29 Hartmann G, Kim H, Piquette-Miller M: Regulation of the hepatic multidrug resistance gene expression by endotoxin and inflammatory cytokines in mice. Int Immunopharmacol 2001;1:189-199.

30 Denk GU, Soroka CJ, Takeyama Y, Chen WS, Schuetz JD, Boyer JL: Multidrug resistanceassociated protein 4 is up-regulated in liver but down-regulated in kidney in obstructive cholestasis in the rat. J Hepatol 2004;40:585591.

31 Zimmermann C, Hruz P, Gutmann H, Terracciano L, Beuers U, Lehmann F, Beglinger C, Drewe J: Decreased expression of breast cancer resistance protein in the duodenum in patients with obstructive cholestasis. $\mathrm{Di}$ gestion 2006;74:101-108.
32 Geick A, Eichelbaum M, Burk O: Nuclear receptor response elements mediate induction of intestinal mdrl by rifampin. J Biol Chem 2001;276:14581-14587.

- 33 Fernandez C, Buyse M, German-Fattal M, Gimenez F: Influence of the pro-inflammatory cytokines on P-glycoprotein expression and functionality. J Pharm Pharm Sci 2004; 7:359-371.

34 Belliard AM, Lacour B, Farinotti R, Leroy C: Effect of tumor necrosis factor-alpha and interferon-gamma on intestinal P-glycoprotein expression, activity, and localization in Caco-2 cells. J Pharm Sci 2004;93:15241536.

35 Evseenko DA, Paxton JW, Keelan JA: Independent regulation of apical and basolateral drug transporter expression and function in placental trophoblasts by cytokines, steroids, and growth factors. Drug Metab Dispos 2007;35:595-601.

36 Eaden J: Review article: Colorectal carcino$\mathrm{ma}$ and inflammatory bowel disease. Aliment Pharmacol Ther 2004;20(suppl 4):2430.

37 Munkholm P: Review article: the incidence and prevalence of colorectal cancer in inflammatory bowel disease. Aliment Pharmacol Ther 2003;18(suppl 2):1-5. 